\title{
Surgical Strategy for Liver Cancers in the Era of Effective Chemotherapy
}

\author{
Junichi Shindoh ${ }^{a} \quad$ Ahmed Kaseb $^{b}$ Jean-Nicolas Vauthey ${ }^{a}$ \\ Departments of ${ }^{a}$ Surgical Oncology and ${ }^{b}$ Gastrointestinal Medical Oncology, The University of \\ Texas MD Anderson Cancer Center, Houston, Tex., USA
}

\section{Key Words}

Hepatocellular carcinoma - Chemotherapy · Systemic therapy

\begin{abstract}
Systemic chemotherapy is the only option for advanced and/or disseminated disease in patients with hepatocellular carcinoma (HCC). For decades, various systemic therapies have been explored for the treatment of advanced HCC. Nevertheless, no satisfactory results have been obtained in cytotoxic chemotherapy so far. However, with the recent introduction of effective chemotherapy agents including sorafenib, the role of systemic therapy for the treatment of $\mathrm{HCC}$ is changing. The goals of systemic therapy include prolongation of survival with stabilization of disease progression and, in selected patients, downsizing of primarily unresectable tumors. In the era of effective chemotherapy, patients with advanced HCC should be managed with individualized approaches to optimize outcome.

Copyright (C) 2013 S. Karger AG, Basel
\end{abstract}

\section{Introduction}

Various therapeutic options are currently available for the treatment of hepatocellular carcinoma (HCC). In patients with a limited number of HCC, surgical resection, liver transplantation, or ablation therapies may offer a chance of cure [1, 2]. In addition, transarterial chemoembolization has been used for patients with multiple tumors $(>3)$ because of its modest effectiveness in control of progression of the disease [3-6]. For the remaining patients with advanced disease, however, only a few treatments have been recommended due to a lack of clinical evidence, and the therapeutic strategy in these patients is not fully established.

Many cytotoxic and biologic agents have been proposed for systemic therapy in patients with HCC. Although sorafenib is currently the only agent with solid clinical evidence $[7,8]$, 


\section{Liver Cancer}

\begin{tabular}{|c|c|}
\hline \multicolumn{2}{|l|}{ Liver Cancer 2013;2:47-54 } \\
\hline $\begin{array}{l}\text { DOI: } 10.1159 / 000346222 \\
\text { Published online: January 7, } 2013\end{array}$ & $\begin{array}{l}\text { (c) } 2013 \text { S. Karger AG, Basel } \\
\text { www.karger.com/lic }\end{array}$ \\
\hline
\end{tabular}

the effectiveness of combination regimens or newly biologic agents have been actively reported during the past decade. In this article, we review clinical results and the state of the art of systemic therapy for HCC, and discuss the treatment strategy in the era of effective chemotherapy.

\section{Systemic Therapy for HCC}

\section{Cytotoxic Chemotherapy}

There have been a large number of studies on the effectiveness of systemic therapy for advanced HCC (table 1). Doxorubicin is one of the most studied agents, and rather favorable outcomes have been reported in its initial studies $[9,10]$. However, the overall response rate for more than 700 patients in recent studies was as low as $18 \%$. Likewise, the effectiveness of other single chemotherapy regimen is generally unsatisfactory.

On the basis of the modest activity of single agents, various combination therapies have been attempted. The most impressive one was the result in a phase II study of a four-drug regimen [cisplatin, interferon (IFN)-alpha-2b, doxorubicin, and 5-fluorouracil (5-FU), PIAF], which showed that 9 out of 50 patients with initially unresectable tumor became amenable to surgery after intensive chemotherapy [11]. However, a follow-up phase III trial comparing PIAF with doxorubicin failed to show an advantage of the combination therapy, with an overall response rate of $17 \%$ [12].

\section{Endocrine Therapy}

Because the tolerability of cytotoxic chemotherapy in patients with HCC is highly influenced by the impaired hepatic function, the effectiveness of noncytotoxic therapies has also been actively studied. It is estimated that estrogen receptors (ERs) are expressed in up to one-third of HCC cases, and the role of sex steroids in the carcinogenesis of HCC has been suggested both in animal models and epidemiologic studies [13]. Therefore, ERs can be a therapeutic target in endocrine therapy for HCC. Although an earlier study investigating the effectiveness of tamoxifen failed to show a prognostic advantage due to gene mutations in ERs [14], a later study of megestrol reported a prognostic advantage in patients with ER-positive HCC (18 vs. 7 months, $p=0.009$ ) [15]. Another possible target in endocrine therapy is the retinoid X receptor $(\mathrm{RXR} \alpha)$, which is malfunctioning in HCC due to phosphorylation by the Ras-MAPK signaling pathway [16]. A recent phase I/II study of an oral synthetic retinoid (TAC-101) has reported good tolerability and a significant disease stabilization effect in 12 out of 21 patients [17]. However, because of the limited number of reports, further investigation is needed to warrant endocrine therapy for HCC.

\section{Biologic Agents}

HCC cells are often intrinsically resistant to chemotherapy through the overexpression of drug transporter proteins including the multidrug resistance gene MDR1. Therefore, cytotoxic agents have generally failed to show a clinically meaningful impact [18]. However, several biologic agents targeting the oncologic signaling pathway of HCC (fig. 1) have demonstrated favorable outcomes in several clinical trials [19-21].

\section{Sorafenib}

Sorafenib is a polyvalent molecule which has been shown in HCC cell line to inhibit the serine-threonine kinase Raf-1 and several receptor tyrosine kinases such as vascular endothelial growth factor receptor-2 (VEGFR2), platelet-derived growth factor receptor 


\section{Liver Cancer}

Table 1. Reported results in phase II/III trials of single-agent and combination cytotoxic chemotherapy in HCC

\begin{tabular}{l}
\hline Liver Cancer 2013;2:47-54 \\
\hline $\begin{array}{l}\text { DOI: 10.1159/000346222 } \\
\text { Published online: January 7, } 2013\end{array}$ \\
$\begin{array}{l}\text { Shindoh et al.: Surgical Strategy for Liver Cancers in the Era of Effective } \\
\text { Chemotherapy }\end{array}$
\end{tabular}

(PDGFR), FLT3, Ret, and c-Kit. To date, two phase III studies (the SHARP trial [7] and the Asia-Pacific trial [22]) demonstrated survival benefit of sorafenib in patients with HCC, and this is the only biologic agent approved for clinical use in systemic therapy for HCC at present.

\section{Antiangiogenic Agents}

Some of the other potential candidates for targeted therapy are antiangiogenic agents. Because HCC is a hypervascular tumor and an association between high VEGF expression and worse survival has been reported [23], inhibition of VEFG may decrease the risk of tumor progression in patients with HCC. Recent studies have shown that the use of bevacizumab either as a single agent or in combination with cy totoxic or molecular targeted agents improves patient survival, with response rate of 12-25\% [24]. The effectiveness of new antiangiogenic agents including sunitinib, brivanib, linifanib, pazopanib, cediranib, vatalanib, and lenalidomide is now under investigation. 
Shindoh et al.: Surgical Strategy for Liver Cancers in the Era of Effective Chemotherapy

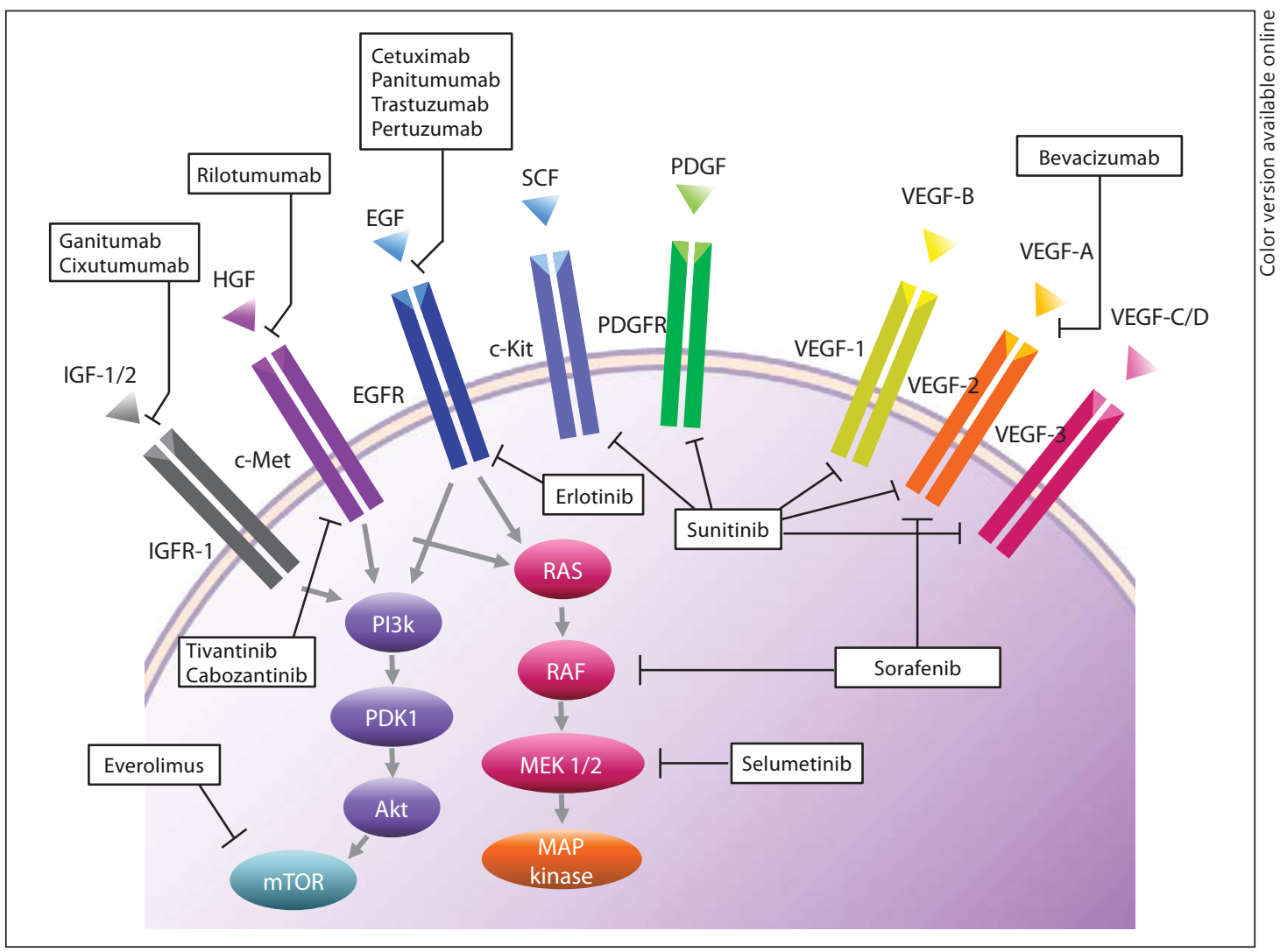

Fig. 1. Molecular pathway and target of systemic therapy in HCC.

\section{Epidermal Growth Factor Receptor Inhibitors}

The expression of epidermal growth factor receptor (EGFR) has also been described in HCC cell lines and tissues. The effectiveness of EGFR tyrosine kinase inhibitors (erlotinib, gefitinib, and lapatinib) or monoclonal anti-EGFR antibodies (cetuximab) has also been investigated. However, other than the modest activity with erlotinib [25], the rest of the EGFR inhibitors failed to show any activity as single agents in advanced HCC.

\section{Other Biologic Agents}

Various new biologic agents including mTOR inhibitors (sirolimus, temsirolimus, and everolimus), a MEK inhibitor (selumetinib), a c-MET inhibitor (tivantinib), and a c-kit inhibitor (cabozantinib) are now under investigation for advanced HCC. Although there has been no single agents showing outstanding effect so far, combination therapy with other cytotoxic and/or biologic agents may offer additional effects in systemic therapy for HCC in selected population [26].

\section{Adjuvant Systemic Therapy for HCC}

Following surgical resection and ablation, tumor recurrence in the form of either local recurrence or de novo carcinogenesis is common. However, because of the unsatisfactory results in systemic therapies for advanced HCC, trials of adjuvant systemic therapy after locoregional treatment have been limited. 
Shindoh et al:: Surgical Strategy for Liver Cancers in the Era of Effective Chemotherapy

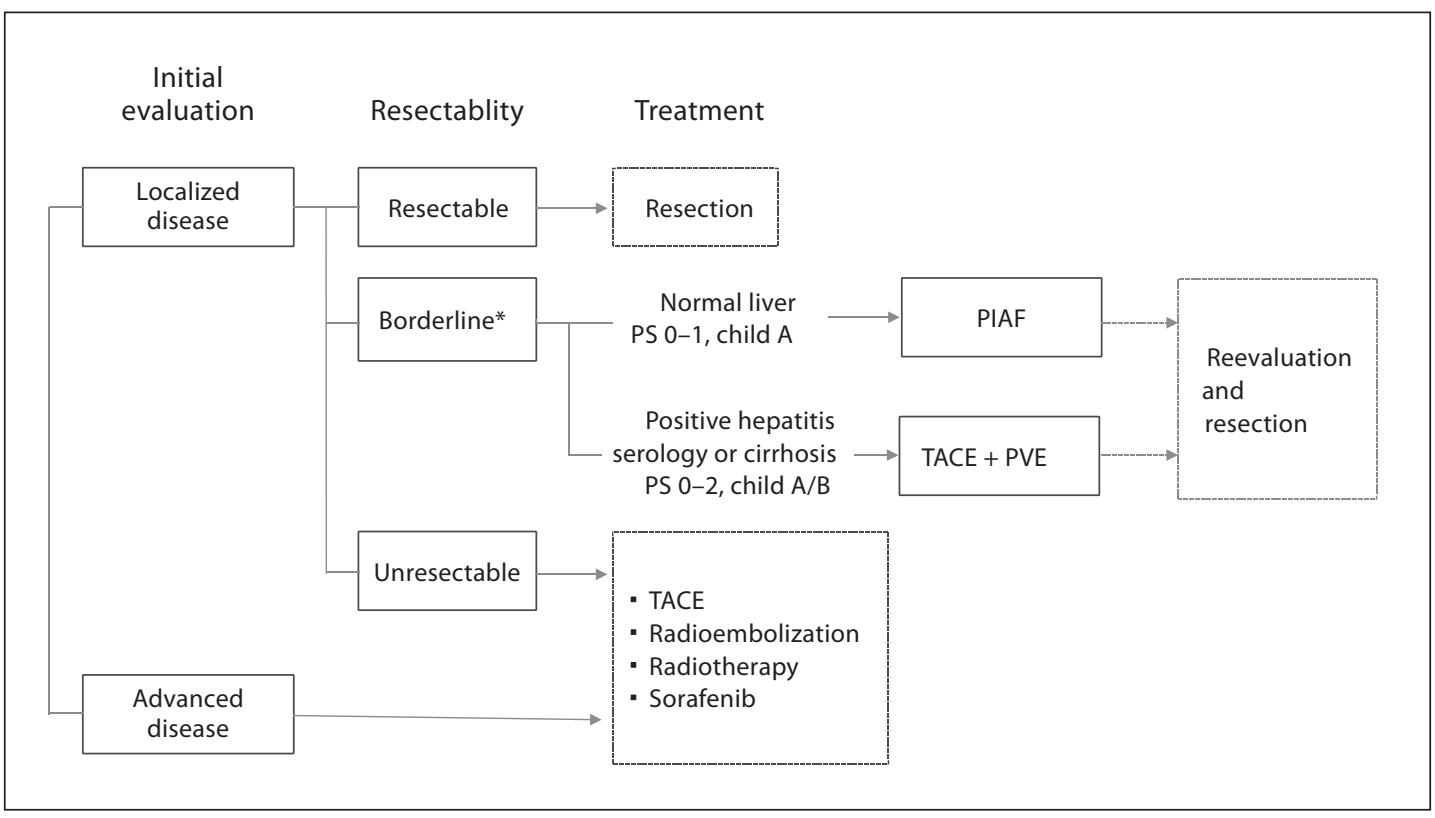

Fig. 2. Treatment strategy for large HCC. * Borderline resectability due to anatomic (size, number, or major vascular invasion) or functional (small future liver remnant) reasons. PS = Performance status; PIAF = cisplatin + interferon + adriamycin + 5-FU; TACE = transarterial chemoembolization; PVE = portal vein embolization.

\section{Systemic Therapy}

Five studies explored the effects of systemic [27-29] or local [30,31] chemotherapy after surgery. However, all of these studies failed to demonstrate prognostic advantage of adjuvant therapy. Therefore, there is no solid evidence supporting the advantage of adjuvant systemic therapy at present. The results in the currently ongoing phase III trial of sorafenib in adjuvant settings (STORM trial) would impact the management of patient care after locoregional treatments in the near future.

\section{Interferon Therapy}

Although the majority of patients with HCC are infected with hepatitis B or C virus, IFN therapy may benefit patients not only by reducing the viral activity but also with its immunomodulatory, antiproliferative, and antiangiogenic activity. A recent meta-analysis of 8 randomized trials showed that adjuvant IFN therapy reduces the risk of 2-year recurrence (risk ratio 0.84; 95\% CI 0.73-0.97) and improves the 2-year overall survival (risk ratio 1.15; 95\% CI 1.07-1.22) [32].

\section{Other Adjuvant Therapies}

Vitamin K2 analog was one of the most studied agents in adjuvant therapy after surgery. Although minor prognostic advantage was suggested in a meta-analysis [32], vitamin K2 analog was not associated with a decreased recurrence rate and its actual prognostic impact is unclear. In addition, the effects of acyclic retinoid or autoimmune therapy were also explored in the past. However, because the effects of these treatments were not outstanding and the number of studies is limited, true advantages of these therapies are still indeterminate. 


\section{Liver \\ Cancer}

\begin{tabular}{l|l}
\hline Liver Cancer 2013;2:47-54 \\
\hline DOI: 10.1159/000346222 & $\begin{array}{l}\text { @ } 2013 \text { S. Karger AG, Basel } \\
\text { www.karger.com/lic }\end{array}$ \\
\hline Published online: January 7, 2013 &
\end{tabular}

Shindoh et al.: Surgical Strategy for Liver Cancers in the Era of Effective Chemotherapy

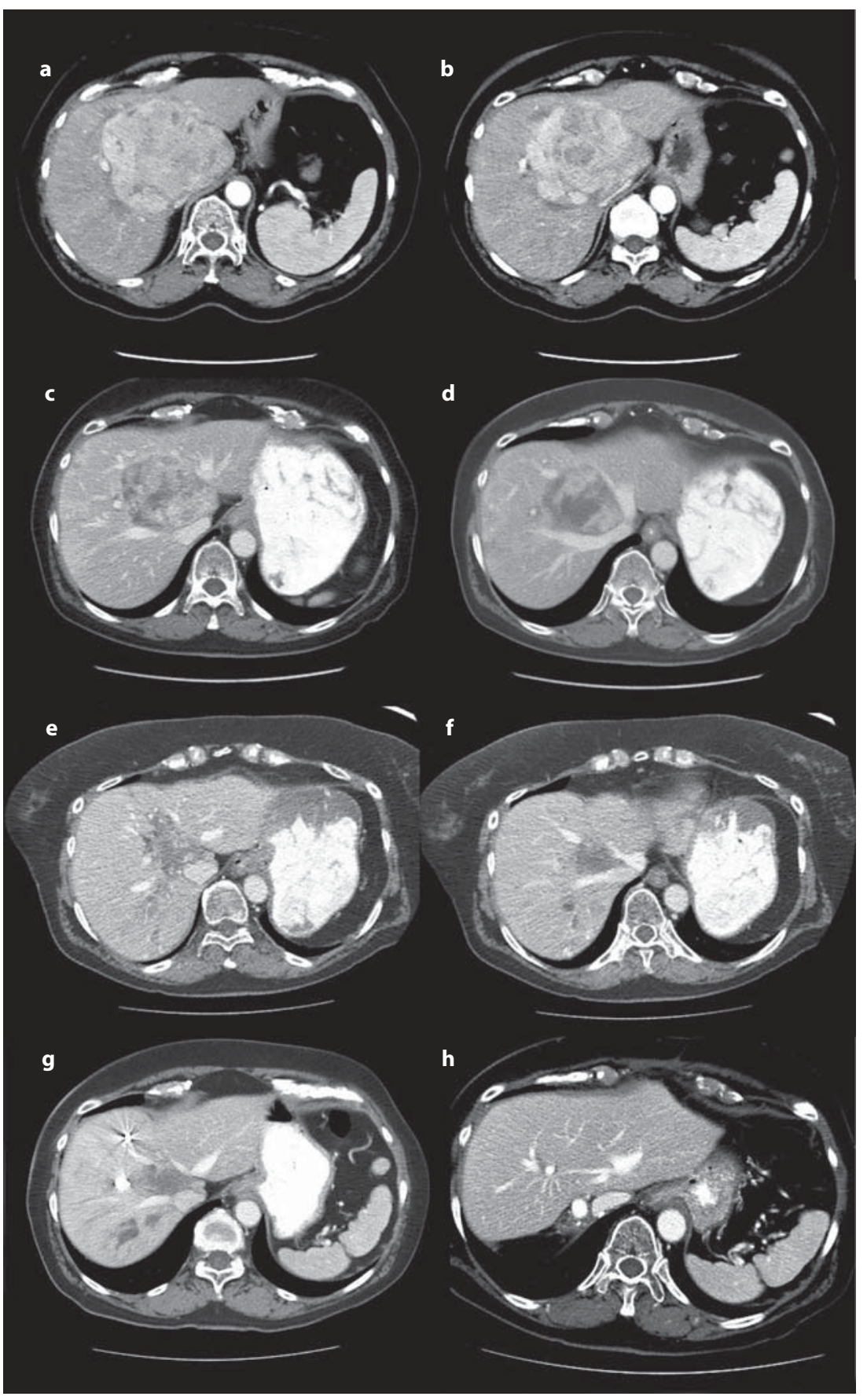

Fig. 3. Imaging of a 68-year-old female with a $10-\mathrm{cm}$ HCC involving the hepatic hilum and the left hemiliver, the right paramedian sector, and abutting the right hepatic vein. $\mathbf{a}$, b Computed tomography after 3 months of sorafenib treatment and 2 sessions of transarterial chemoembolization. c, d Computed tomography after 7 cycles of PIAF therapy. e, f Preoperative imaging after right portal vein embolization excluded to segment IV. $\mathbf{g}$ Twelve months after extended right hepatectomy (h). 


\section{The Role of Systemic Therapy in a Multidisciplinary Approach for HCC}

Although only a few evidences have been available in systemic therapy for HCC, there exists a minority of patients who respond well to systemic therapy for primarily unresectable or metastatic HCC. The goals of systemic therapy include (1) the conversion of unresectable to resectable disease in patients with preserved liver function and performance status, and (2) the palliation and prolonged survival in patients with advanced disease. Figure 2 shows the treatment strategy for large HCC at the MD Anderson Cancer Center. For patients diagnosed with borderline resectable tumors, intensive multiagent systemic therapy or sequential transarterial chemoembolization and portal vein embolization is selected based on the patients' histopathologic status of underlying liver, hepatitis serology, hepatic function, and performance status, expecting increased resectability. Although the effectiveness of the PIAF regimen has not yet been fully understood, our preliminary results suggest that a modified PIAF regimen is associated with improved tolerability and such regimen may contribute to improve the resection rate and survival in a selected population with good performance status and without chronic hepatitis (fig. 3 ).

\section{Conclusion}

Although considerable efforts have been made for decades in exploration of effective systemic therapy, there has been no study reporting an outstanding result in chemotherapy for HCC. However, with the introduction of sorafenib and the increasing use of other biologic agents, various candidate regimens are now under investigation. The goals of systemic therapy include the prolongation of survival through stabilization of disease progression and the selection of the candidates for curative resection by downsizing the primarily unresectable tumor. In this era of effective chemotherapy, patients with advanced HCC should be managed in a multidisciplinary approach to maximize the treatment outcome, and our preliminary data support the rationale and preferable outcome of such an approach.

\section{Acknowledgment}

The University of Texas MD Anderson Cancer Center is supported in part by the National Institutes of Health through Cancer Center Support Grant CA016672.

\section{Conflicts of Interest}

The authors have nothing to disclose.

\section{References}

1 Belghiti J, Fuks D: Liver resection and transplantation in hepatocellular carcinoma. Liver Cancer 2012;1: 71-82.

2 Cheah YL, Chow P: Liver transplantation for hepatocellular carcinoma: an appraisal of current controversies. Liver Cancer 2012, in press.

3 Kudo M, Izumi N, Kokudo N, Matsui O, Sakamoto M, Nakashima O, et al: Management of hepatocellular carcinoma in Japan: Consensus-Based Clinical Practice Guidelines proposed by the Japan Society of Hepatology (JSH) 2010 updated version. Dig Dis 2011;29:339-364.

4 Mazzaferro V, Regalia E, Doci R, Andreola S, Pulvirenti A, Bozzetti F, et al: Liver transplantation for the treatment of small hepatocellular carcinomas in patients with cirrhosis. N Engl J Med 1996;334:693-699. 
Llovet JM, Burroughs A, Bruix J: Hepatocellular carcinoma. Lancet 2003;362:1907-1917.

Llovet JM, Ricci S, Mazzaferro V, Hilgard P, Gane E, Blanc JF, et al: Sorafenib in advanced hepatocellular carcinoma. N Engl J Med 2008;359:378-390.

- 8 Kudo M: Treatment of advanced hepatocellular carcinoma with emphasis on hepatic arterial infusion chemotherapy and molecular targeted therapy. Liver Cancer 2012;1:62-70.

9 Johnson PJ, Williams R, Thomas H, Sherlock S, Murray-Lyon IM: Induction of remission in hepatocellular carcinoma with doxorubicin. Lancet 1978;1:1006-1009.

$\checkmark 10$ Olweny CL, Toya T, Katongole-Mbidde E, Mugerwa J, Kyalwazi SK, Cohen H: Treatment of hepatocellular carcinoma with adriamycin. Preliminary communication. Cancer 1975;36:1250-1257.

11 Leung TW, Patt YZ, Lau WY, Ho SK, Yu SC, Chan AT, et al: Complete pathological remission is possible with systemic combination chemotherapy for inoperable hepatocellular carcinoma. Clin Cancer Res 1999;5: 1676-1681.

12 Yeo W, Mok TS, Zee B, Leung TW, Lai PB, Lau WY, et al: A randomized phase III study of doxorubicin versus cisplatin/interferon alpha-2b/doxorubicin/fluorouracil (PIAF) combination chemotherapy for unresectable hepatocellular carcinoma. J Natl Cancer Inst 2005;97:1532-1538. De Maria N, Manno M, Villa E: Sex hormones and liver cancer. Mol Cell Endocrinol 2002;193:59-63.

14 Liu CL, Fan ST, Ng IO, Lo CM, Poon RT, Wong J: Treatment of advanced hepatocellular carcinoma with tamoxifen and the correlation with expression of hormone receptors: a prospective randomized study. Am J Gastroenterol 2000;95:218-222.

15 Villa E, Ferretti I, Grottola A, Buttafoco P, Buono MG, Giannini F, et al: Hormonal therapy with megestrol in inoperable hepatocellular carcinoma characterized by variant oestrogen receptors. Br J Cancer 2001;84: 881-885.

16 Shimizu M, Sakai H, Moriwaki H: Chemoprevention of hepatocellular carcinoma by acyclic retinoid. Front Biosci 2011;16:759-769.

-17 Higginbotham KB, Lozano R, Brown T, Patt YZ, Arima T, Abbruzzese JL, et al: A phase I/II trial of TAC-101, an oral synthetic retinoid, in patients with advanced hepatocellular carcinoma. J Cancer Res Clin Oncol 2008;134:1325-1335.

18 Lopez PM, Villanueva A, Llovet JM: Systematic review: evidence-based management of hepatocellular carcinoma - an updated analysis of randomized controlled trials. Aliment Pharmacol Ther 2006;23:15351547.

19 Llovet JM, Bruix J: Testing molecular therapies in hepatocellular carcinoma: the need for randomized phase II trials. J Clin Oncol 2009;27:833-835.

-20 Moeinia A, Cornellà H, Villanueva A: Emerging signaling pathways in hepatocellular carcinoma. Liver Cancer 2012;1:83-93.

21 Finn RS: Current and future treatment strategies for patients with advanced hepatocellular carcinoma: role of mTOR inhibition. Liver Cancer 2012, in press.

22 Cheng AL, Kang YK, Chen Z, Tsao CJ, Qin S, Kim JS, et al: Efficacy and safety of sorafenib in patients in the Asia-Pacific region with advanced hepatocellular carcinoma: a phase III randomised, double-blind, placebo-controlled trial. Lancet Oncol 2009;10:25-34.

23 Poon RT, Ho JW, Tong CS, Lau C, Ng IO, Fan ST: Prognostic significance of serum vascular endothelial growth factor and endostatin in patients with hepatocellular carcinoma. Br J Surg 2004;91:1354-1360.

24 Tazi el M, Essadi I, M’Rabti H, Touyar A, Errihani PH: Systemic treatment and targeted therapy in patients with advanced hepatocellular carcinoma. N Am J Med Sci 2011;3:167-175.

25 Philip PA, Mahoney MR, Allmer C, Thomas J, Pitot HC, Kim G, et al: Phase II study of Erlotinib (OSI-774) in patients with advanced hepatocellular cancer. J Clin Oncol 2005;23:6657-6663.

-26 Thomas MB, Tetzlaff E, Lozano R, Samp L, Butler CE, Gannon C, et al: Curing hepatocellular carcinomatosis with biologic therapy and surgery: achieving the impossible? J Surg Oncol 2008;97:82-84.

27 Hasegawa K, Takayama T, Ijichi M, Matsuyama Y, Imamura H, Sano K, et al: Uracil-tegafur as an adjuvant for hepatocellular carcinoma: a randomized trial. Hepatology 2006;44:891-895.

-28 Xia Y, Qiu Y, Li J, Shi L, Wang K, Xi T, et al: Adjuvant therapy with capecitabine postpones recurrence of hepatocellular carcinoma after curative resection: a randomized controlled trial. Ann Surg Oncol 2010;17: 3137-3144.

29 Yamamoto M, Arii S, Sugahara K, Tobe T: Adjuvant oral chemotherapy to prevent recurrence after curative resection for hepatocellular carcinoma. Br J Surg 1996;83:336-340.

-30 Kim do Y, Ahn SH, Kim SU, Choi SB, Lee KH, Park MS, et al: Adjuvant hepatic arterial infusional chemotherapy with 5-fluorouracil and cisplatin after curative resection of hepatocellular carcinoma. Oncology 2011;81:184-191.

31 Lai EC, Lo CM, Fan ST, Liu CL, Wong J: Postoperative adjuvant chemotherapy after curative resection of hepatocellular carcinoma: a randomized controlled trial. Arch Surg 1998;133:183-188.

32 Zhong JH, Li H, Li LQ, You XM, Zhang Y, Zhao YN, et al: Adjuvant therapy options following curative treatment of hepatocellular carcinoma: a systematic review of randomized trials. Eur J Surg Oncol 2012;38:286-295. 